\title{
Timing of Surgery for Spinal Fractures Associated with Systemic Trauma: A Need for a Strategic and Systemic Approach
}

\author{
Ismet KOKSAL ${ }^{1}$, Fatih ALAGOZ², Haydar CELIK³ ${ }^{3}$ Ali Erdem YILDIRIM², Tezcan AKIN ${ }^{4}$, Yahya GUVENC ${ }^{5}$, \\ Mete KARATAY ${ }^{3}$, Yavuz ERDEM ${ }^{3}$ \\ ${ }^{1}$ Yenimahalle State Hospital, Department of Orthopaedics and Traumatology, Ankara, Turkey \\ ${ }^{2}$ Ankara Numune Education and Research Hospital, Department of Neurosurgery, Ankara, Turkey \\ ${ }^{3}$ Ankara Education and Research Hospital, Department of Neurosurgery, Ankara, Turkey \\ ${ }^{4}$ Ankara Numune Education and Research Hospital, Department of General Surgery, Ankara, Turkey \\ ${ }^{5}$ Sincan State Hospital, Department of Neurosurgery, Ankara, Turkey
}

\section{ABSTRACT}

AIM: An underestimated evaluation of systemic organs in cases with spinal fractures might jeopardize the intervention for treatment and future complications with an increased morbidity and mortality are almost warranted. In the present study, a retrospective analysis of spinal fracture cases associated with systemic trauma was performed to assess surgical success.

MATERIAL and METHODS: A retrospective analysis of patients with thoracolumbar fractures who were admitted to the emergency unit between September 2012 and September 2014 was used for the study. The cases were categorized according to age, sex, reason of trauma, associated trauma, neurological condition and treatment details and results were analysed using SPSS 14.0 for Windows.

RESULTS: The most common reason of trauma is detected as falls in 101 cases (64.3\%). Radiological evaluation of spinal fractures revealed a compression fracture in 106 cases (67.5\%) and other fractures in 51 cases (32.5\%). Surgical treatment for spinal fracture was performed in $60.5 \%$ of the cases and conservative approach was preferred in $39.5 \%$ cases. In non-compressive spinal fractures, an associated pathology like head trauma, lower extremity fracture or neurological deficit was found to be higher in incidence $(p<0.05)$. Necessity for surgical intervention was found to be more prominent in this group $(p<0.05)$. However, the fracture type was not found to be associated with morbidity and mortality $(\mathrm{p}<0.05)$.

CONCLUSION: A surgical intervention for a spinal fracture necessitating surgery should rather be performed right after stabilization of the systemic condition which might be associated with decreased morbidity and mortality.

KEYWORDS: Systemic trauma, Spinal fracture, Timing of surgery

\section{INTRODUCTION}

Improved use of technology has resulted in an increased number of motor vehicles and higher skyscrapers which probably have a role in increased severity of trauma (26). It is well known that the spinal fractures are associated with high- energy trauma (7) and an increased incidence in systemic and spinal trauma is not striking. Dislocations and burst fractures of the thoracolumbar region are associated with high energy trauma and osteoporotic fractures of the regarding region might develop even after a low energy trauma $(22,25)$. 
Spinal fractures develop after high-energy forces in diverse directions and injury of other body systems might almost be inevitable (7). Thus clinical situation involving other systems is overwhelmingly important in the selection of treatment approach. Distinctive factors in the treatment of traumatic spinal fractures can be defined as the presence of neurological deficit and progression of the regarding injury (7). It is widely accepted that a relatively urgent surgical approach might be associated with decreased risk of complications regarding immobility $(5,13,22)$. On the other hand, preservation of critical life measures after systemic trauma aids in balanced systemic status and diminished risk of successive interventions. In the present study, plan and timing of surgical intervention were studied after admission to emergency wards in patients with systemic trauma and spinal fracture.

\section{MATERIAL and METHODS}

A total of 157 patients who were admitted to Ankara Numune and Ankara Education and Research Hospitals between September 2012 and September 2014 were retrospectively analyzed for systemic trauma and thoracolumbar fractures. Neurological condition at the time of diagnosis and detailed radiological analyses were thoroughly evaluated for the study. According to the multi-trauma protocol at the emergency wards of our center, radiological scans of head, thorax, abdomen and major extremities were performed. The cases were categorized according to age, sex, reason of trauma, associated trauma, fracture type, neurological condition and treatment details and results were statistically analyzed. Patients who have minor fractures including transverse and spinous process fractures were all excluded from the study.

Vital functions including blood pressure, blood hemoglobin and oxygen levels were all evaluated in patients presenting with systemic trauma. Patients with deteriorated functions due to associated pathologies like brain or lung contusion, abdominal injury, pelvis or long extremity fractures were meticulously evaluated to attain a stable level of vital signs.

Systemic influence of all regarding pathologies were corrected before surgical intervention and patients were operated after detailed radiological studies. Computed tomography (CT) and direct X-rays were evaluated for McCormack score and posterior stabilization was preferred for patients with a score between 4 and 6 . Patients with a score of 7 or over were operated by posterior stabilization and anterior fusion technique. Patients with a score of 5 or more on magnetic resonance imaging (MRI) in accordance with the thoracolumbar injury classification and severity (TLICS) score were subjected to surgical treatment whereas patients with a score of 3 or less were treated with conservative measures. Patients with a score of 4 were subjected to conservative or surgical measures depending on other scores and associated systemic injury.

All data were evaluated with Statistical Package for Social Sciences (SPSS) 19.0 for Windows. Numerical variables were further analyzed with the Kolmogorov-Smirnov test to check normal distribution. Descriptive statistics were defined as mean $\pm S D$ (standard deviation) and categorical variables were shown as number of cases ( $n$ ) and percentages (\%). Categorical variables were analyzed with chi square test. $\mathrm{P}$ values below $0.05(p<0.05)$ were accepted as significant.

\section{RESULTS}

Mean age of patients included into the study was calculated as $47.7 \pm 16.9$ years. 94 cases were male (59.9\%) and 63 (40.1\%) were female. The most common cause of trauma was detected as falls from a height in $64.3 \%$ of cases. Motor vehicle accidents were the second common etiological factor with 38 cases $(24.2 \%)$. Number of work accidents was 18 $(11.5 \%)$ and they form the third common cause of spinal fractures. Number of cases with compression fractures was $106(67.5 \%)$ and patients with non-compressive fractures were 51 (32.5\%). Sixty-five cases (41.4\%) were reported to have an associated injury necessitating surgical intervention and lower extremity fracture (25 cases, $15.9 \%$ ) was found to be most prominent. Neurological deficit was noted in 11 cases (19.6\%) and 60.5 percent of cases were treated with surgical measures. Mortality and morbidity rates were found as 1.3 and $1.9 \%$ respectively (Table I).

One patient from compression trauma group was lost due to pulmonary embolus and one patient from non-compressive trauma group died because of cerebrovascular occlusive event (Both patients had lower extremity fractures).

Systemic functions (blood pressure, blood oxygen saturation and hemoglobin levels etc.) were corrected primarily. Associated injuries such as head trauma, lung contusion, abdominal injury, pelvis and extremity fractures (65 cases, $41.4 \%$ ) were stabilized before a surgical intervention. Patients having systemic trauma (34 cases, $21.6 \%$ ) were operated in an elective urgent basis.

Strategy and indication of surgical intervention was determined according to the McCormack score and TLICS classification. 53 patients (50\%) with a McCormack score between 4 and 6 and TLICS score of 5 or over were operated using posterior stabilization. Fifty-one patients with a non-compressive fracture were evaluated with the same scoring system and 42 cases $(82.4 \%)$ were operated using posterior stabilization. Six patients with a McCormack score of 7 or over were operated by posterior stabilization and anterior fixation. Reasons of morbidity were lower extremity motor deficit after posterior stabilization in one and peroneal-posterior tibial nerve at the postoperative period of lower extremity fracture surgery in another case.

There was no statistical correlation between fracture type and type of injury $(p<0.05)$. Associated injuries and neurological deficit were found to be more prominent in non-compressive fractures $(p<0.05)$. Surgery was required more in non-compressive fractures $(p<0.05)$ nevertheless there was no statistical correlation with fracture type, mortality and morbidity (Table II) $(\mathrm{p}>0.05)$.

\section{DISCUSSION}

Despite the presence of protective anatomic structures, interfacet connections preserving joint stability, thoracolumbar 
Table I: Demographic Results

\begin{tabular}{|c|c|c|}
\hline & & $\begin{array}{c}\text { Mean } \pm \text { SD/N } \\
(\%)\end{array}$ \\
\hline Age & & $47.7 \pm 16.9$ \\
\hline \multirow{2}{*}{ Sex } & Male & $94(59.9)$ \\
\hline & Female & $63(40.1)$ \\
\hline \multirow{3}{*}{ Type of trauma } & Vehicle accidents & $38(24.2)$ \\
\hline & Work accidents & $18(11.5)$ \\
\hline & Falls from a height & $101(64.3)$ \\
\hline \multirow[t]{2}{*}{$\begin{array}{l}\text { Mechanism of } \\
\text { trauma }\end{array}$} & Compression & $106(67.5)$ \\
\hline & Burst & $51(32.5)$ \\
\hline \multicolumn{2}{|l|}{ Associated injury } & $65(41.4)$ \\
\hline \multirow{6}{*}{$\begin{array}{l}\text { Type of } \\
\text { associated } \\
\text { injury }\end{array}$} & Head & $7(4.5)$ \\
\hline & Abdomen & $19(12.1)$ \\
\hline & Thorax & $15(9.6)$ \\
\hline & Upper extremity & $16(10.2)$ \\
\hline & Pelvis & $9(5.7)$ \\
\hline & Lower extremity & $25(15.9)$ \\
\hline $\begin{array}{l}\text { Neurological } \\
\text { deficit }\end{array}$ & & $11(7.0)$ \\
\hline \multirow{2}{*}{$\begin{array}{l}\text { Type of } \\
\text { treatment }\end{array}$} & Surgery & $95(60.5)$ \\
\hline & Conservative & $62(39.5)$ \\
\hline \multirow{3}{*}{ Result } & Exitus & $2(1.3)$ \\
\hline & Morbidity & $3(1.9)$ \\
\hline & Improved & $152(96.8)$ \\
\hline
\end{tabular}

region is one of the most vulnerable region for trauma due to high range of motion and other anatomic factors (8). Thoracolumbar region is reported as the most common area for spine fractures in Turkish national and international studies. In several multicenter studies, thoracolumbar fractures are most common at T1-L1 level followed by L2-L5 levels and similar results were noted in our national studies $(2,3,12)$.

Compression fractures are fractures involving anterior column and rarely associated with neurological injury. Anterior column fractures are usually stable. However burst fractures are usually unstable and associated with middle column injury. Spinal cord is usually accepted to be instable at circumstances of failed fusion, loss of height over 50 percent, kyphosis with angulation more than 20 degrees, multilevel fractures and associated neurological injury (7).

Mean age of patients was 42.6 years and 80.6 of them were male as released from National Spinal Cord Injury Statistical Center (NSCISC). The national studies performed at our country were compatible with results of NSCISC and majority of patients were male $(19,21,26)$. In the present study, mean age was calculated as 47.7 and $59.9 \%$ of patients were male. The main reasons might be relatively more active physical performance of males within the social life and increased use of motor vehicles.

Ghobrial et al. reported that burst fractures constitute as high as $45 \%$ of all thoracolumbar fractures (13). Another study by Been and Bouma reported a rate of $49 \%$ (4). In the present study, the compression fracture rate was significantly higher than burst fracture. The main reasons might be relatively high proportion of work accidents and motor vehicle injuries. It should be noted that the energy produced at work accidents and motor vehicle injuries is lower when compared to falls from a height. Furthermore the angle of force is horizontal and ends in wedge fractures according to our belief. On the other hand, the angle of force in falls from a height is vertical which easily give rise to burst fractures.

Many studies regarding spinal cord trauma demonstrated that motor vehicle accidents are the most frequent reason followed by falls from a height and other reasons $(16,20,24)$. Been and Bouma reported falls from a height as the most common reason of thoracolumbar fractures (4). In another study, motor vehicle accidents were found to be most frequent reason of thoracolumbar fractures (19). Ucar et al. reported falls from a height to be most common (23). In the present study, falls from a height was found to be most frequent and to our belief the main reasons are insufficient laws regulating the safety at work, increased suicidal attempts within the last decade and traditional habit of sleeping at roof in some rural areas of Turkey. Burst fractures form the major group among falls from a height in the present study and this might be due to relatively higher energy exposure at a fall from a height.

An associated injury was reported in almost half of the thoracolumbar fractures $(1,17,26)$. Saboe et al. reported that the most frequently associated trauma is head injury and the incidence of extremity trauma is $23 \%$ (17). In another study, the incidence of pelvic and lower extremity fracture was found to be highest due to the high energy of lumbar fractures (18). In the present study, incidence of an associated injury was detected to be highest in burst fractures and the main reason might be the necessity of a high energy to produce a lumbar fracture. Furthermore, the incidence of lower extremity fractures was reported at a higher incidence since the spread of energy at a fall from a height is from the lower extremity to spinal column vertebrae. We propose that the incidence of head trauma, extremity fractures and pelvis trauma was found to be highest not only due to energy level but also due to plane of energy.

There are reports which point to a stable clinical status of burst fractures despite a relative tendency for a neurological deficit due to separated bone fragments $(2,8)$. The main reasons of neurological deficit are vascular ischemia, edema or hematoma of the spinal cord and cauda equina fibers at the time of injury $(2,6,7,15)$. Ghobrial et al. reported a neurological deficit in almost half of the cases with burst fractures (13). Neurological deficit risk was relatively lower since the major site of injury 
Table II: The Relation Between Fracture Type and Characteristics of Injury

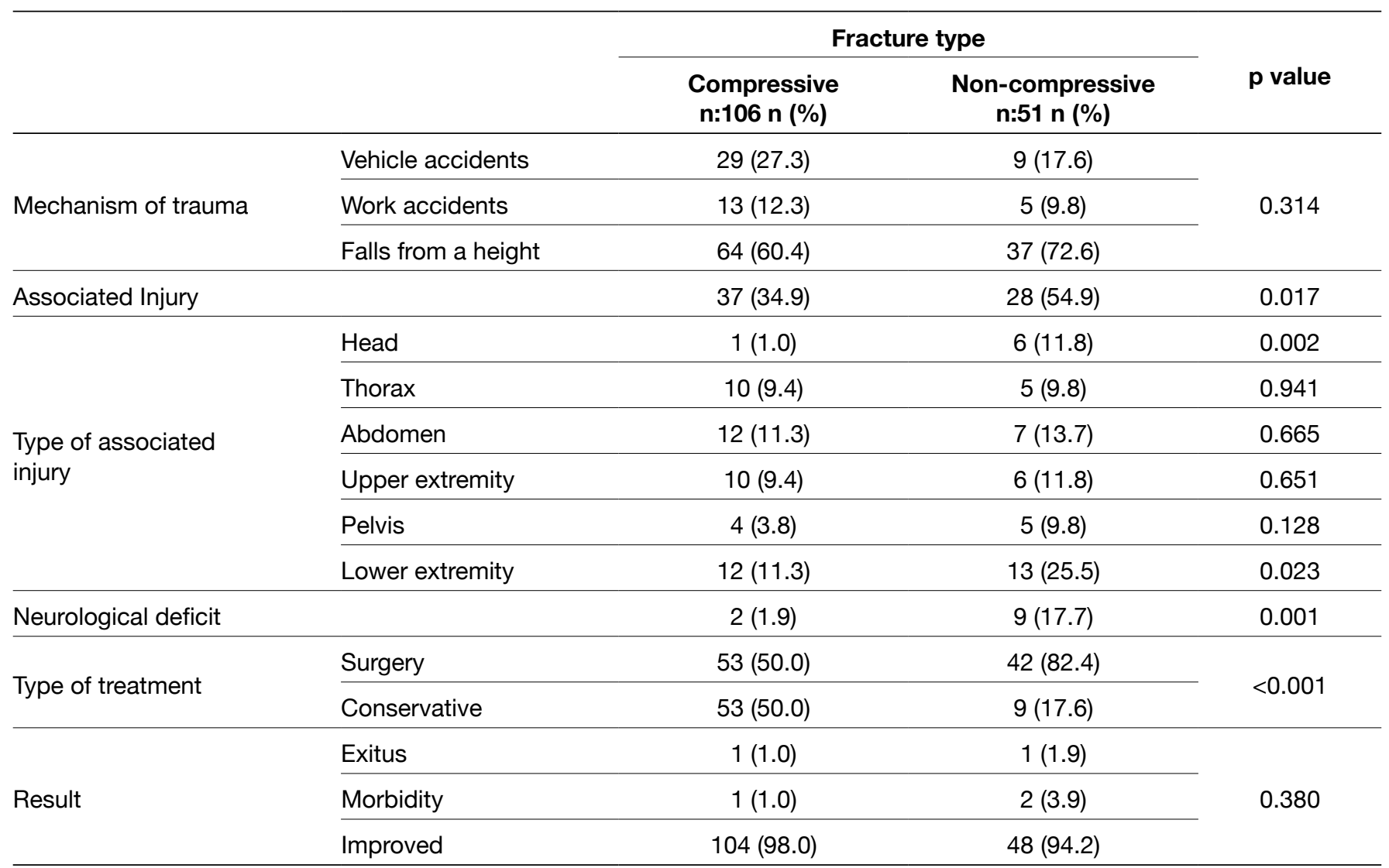

was the body of vertebrae (7). In our study, neurological deficit risk was relatively high due to hematoma, edema, increased vascular injury risk and spinal cord injury due to separated fragments and a high energy is undoubtedly associated with non-compressive fractures. Surgical treatment is preferred instead of conservative management since a spinal column alignment, stabilization and an ideal canal width might be provided earlier $(7,14)$. Partial neurological injury, progressive neurological deficit and spinal canal stenosis necessitates an immediate surgical intervention in lumbar fractures (7). However neurological improvement was not confirmed with a surgical correction (19). In the present study, surgery was most likely preferred in burst fractures due to higher incidence of associated neurological injury and separated bone fragments compromising spinal canal. An associated high energy in these fractures might raise doubt for a progressive neurological deficit hence an increased tendency for surgical correction.

Despite the improvements in design of vehicles, recovery of safety precautions and more advanced first aid equipments, the mortality rate due to spinal cord injuries is still as high as $16 \%$. A significant decline of mortality rate within the last few decades should not be denied. The reasons of mortality are usually due to associated trauma and secondary infections
$(9-11,16,22)$. Ghobrial et al. also pointed to the importance of relation between associated trauma incidence and increased risk of mortality. Their morbidity rate was $4.35 \%$ and compatible with the reported incidences in the literature (13). The morbidity rate reported in the present study was compatible with the results of the literature and the mortality rate was relatively low. The main reasons might be a strategy of patient admission after correction of vital signs and exclusion and correction of associated trauma. The reported rate in the literature might be associated not only with thoracolumbar trauma but also with delays in access to the hospital. Time delays in transfer or massive bleeding at transfer or accident location further influence this rate. A high mortality rate due to pulmonary emboli and cerebrovascular accidents supports our theory that mortality rate is highest before admission to the medical center.

The results above showed that there was no correlation between fracture type and morbidity or mortality rates. In conclusion, incidence of neurological deficit and an associated systemic pathology was found to be highest in non-compressive fractures due to high energy trauma verifying a more pronounced benefit from an earlier surgical intervention. 


\section{REFERENCES}

1. Acaroğlu ER, Alanay A: Four-level noncontiguous fracture of the vertebral column: A case report. J Orthop Trauma 15:294299, 2001

2. Alıcı E, Kırımca M, Göçen S, Berk H, Aksu G: Neurological deficit in relation to the canal encroachment, level and type of the thoracolumbar fractures. Turkish J Spine Surgery 8:39-42, 1997

3. Argün $M$, Turk CY, Şahin V, Usta C: Surgical treatment of thoracolumbar vertebrae fractures with Alıcı Spinal Instrumentation. Turkish J Spine Surgery 8:43-48,1997

4. Been HD, Bouma GJ: Comparison of two types of surgery for thoraco-lumbar burst fractures: Combined anterior and posterior stabilisation vs. posterior instrumentation only. Acta Neurochir (Wien) 141:349-357,1999

5. Bellabarba C, Fisher C, Chapman JR, Dettori JR, Norvell DC: Does early fracture fixation of thoracolumbar spine fractures decrease morbidity or mortality? Spine (Phila Pa 1976) 35(9 Suppl):S138-145,2010

6. Berk H, Akseki D, Yaldız K: The role of posterior instrumentation on canal compromise in the treatment of burst fractures of the thoracolumbar spine. Turkish J Spine Surgery 5:71-74, 1994

7. Berk H: Sırt-bel omur kırıkları. TOTBiD Derg 7(1-2):20-34, 2008 (in Turkish)

8. Çetinus E, Hüner H, Akyıldız M, Cever İ: Burst kırı̆̆ı sonrasında spinal kanalın remodelasyonu (vaka takdimi). Acta Orthop Traumatol Turc 27:276-279,1993 (in Turkish)

9. DeVivo MJ, Krause JS, Lammertse DP: Recent trends in mortality and causes of death among persons with spinal cord injury. Arch Phys Med Rehabil 80:1411-1419,1999

10. Dryden DM, Saunders LD, Rowe BH: The epidemiology of traumatic spinal cord injury in Alberta, Canada. Can J Neurol Sci 30:113-121,2003

11. Frankel HL, Coll JR, Charlifue SW: Long-term survival in spinal cord injury: A fifty year investigation. Spinal Cord 36:266-274, 1998

12. Gertzbein SD: Scoliosis research society: Multicenter spine fractures study. Spine 17(5):528-540,1992

13. Ghobrial GM, Maulucci CM, Maltenfort M, Dalyai RT, Vaccaro AR, Fehlings MG, Street J, Arnold PM, Harrop JS: Operative and nonoperative adverse events in the management of traumatic fractures of the thoracolumbar spine: A systematic review. Neurosurg Focus 37(1):E8, 2014
14. Jacobs RR, Asher MA, Snider RK: Thoracolumbar spine injuries. A comparative study of recumbent and operative treatment in 100 patients. Spine 5:463-477,1980

15. Kim NH, Lee HM, Chun IM: Neurologic injury and recovery in patients with burst fracture of the thoracolumbar spine. Spine 24:290-293,1999

16. National Spinal Cord Injury Statistical Center: Spinal cord injury facts and figures at a glance.Feburay $2013 \mathrm{https} / / /$ www.nscisc.uab.edu /PublicDocuments /fact_figures_docs / Facts\% 202013.pdf, Accessed on 03.10.2014

17. Saboe LA, Reid DC: Spine trauma and associated injuries. J Trauma 31:43-48,1991

18. Stanislas MJ, Latham JM, Porter KM, Alpar EK, Stirling AJ: A high risk group for thoracolumbar fractures. Injury 29(1):1518, 1998

19. Tabak AY, Günay MC, Altay M, Türker HB: Effects of shortand long-segment posterior instrumentation on spinal canal remodeling in thoracolumbar vertebra burst fractures. Ulus Travma Acil Cerrahi Derg 17(2):141-148, 2011

20. Thurman DJ, Burnett CL, Jeppson L, Beaudoin DE, Sniezek JE: Surveillance of spinal cord injuries in Utah, USA. Paraplegia 32:665-669,1994

21. Tonbul M, Yılmaz MR, Özbaydar MU, Adaş M, Altan: Longterm results of conservative treatment for thoracolumbar compression fracture. Acta Orthop Traumatol Turc 42(2):8083, 2008

22. Torun F, Kalkan E, Çiçek O, Erdi F: Ağrılı lomber vertebra çökme kırığı ve lumbosakral spondilolistezisi olan bir vakada tedavi. Genel Tıp Derg 16(4):199-201, 2006 (in Turkish)

23. Uçar S Varer M, Dirim B, Apaydın M, Dirik M, Uluç E: The relationship between the spinal canal diameter and the neurological deficit severity in spinal injuries. EÜ Tıp Fakültesi Derg 19(1):7-14, 2005

24. Vaccaro AR, Lehman RA Jr, Hurlbert RJ, Anderson PA, Harris M, Hedlund R, Harrop J, Dvorak M, Wood K, Fehlings MG, Fisher C, Zeiller SC, Anderson DG, Bono CM, Stock GH, Brown AK, Kuklo T, Oner FC: A new classification of thoracolumbar injuries: The importance of injury morphology, the integrity of the posterior ligamentous complex, and neurologic status. Spine 30(20):2325-2333, 2005

25. Wasnich RD: Vertebral fracture epidemiology. Bone 18 Suppl 3:179-183,1996

26. Yetiş M: Torakolomber burst kırıklarında posterior enstrumantasyon ve füzyon sonuçlarımız (Uzmanlık Tezi), İstanbul: 2009 (in Turkish) 